\section{Commentary: Hybrid repair of acute type $A$ aortic dissection with visceral malperfusion syndrome- endovascular first!}

\author{
Oliver J. Liakopoulos, MD, ${ }^{\mathrm{a}}$ and Wael Ahmad, $\mathrm{MD}^{\mathrm{b}}$
}

Mesenteric malperfusion syndrome (MMP) caused by acute type A dissection (AAD) is a rare, often clinically silent and fatal complication. ${ }^{1}$ In the prospective, multicentric German Registry for Acute Aortic Dissection Type A and the International Registry for Acute Dissection (IRAD), mesenteric malperfusion was present in 5.8\% (2137 patients) and 3.8\% (1809 patients), respectively. ${ }^{2,3}$ As reported from the IRAD registry, hospital mortality was $95 \%$ with medical (conservative) therapy, $72 \%$ after endovascular, and $42 \%$ after surgical/hybrid treatment of AAD complicated by MMP and ultimately linked to a 3- to 4fold greater mortality compared with patients without malperfusion. ${ }^{1,3}$ Strikingly, approximately $50 \%$ of patients with MMP in the IRAD registry did not receive a surgical treatment, despite the dismal results of a watchful-wait strategy. ${ }^{3}$

The optimal management of AAD with MMP still remains controversial, and current surgical strategies include immediate proximal aortic repair with or without laparotomy, immediate proximal aortic repair with downstream endovascular repair of the aorta (endovascular-second strategy), and downstream endovascular repair first with delayed open surgical repair of the ascending aorta/arch

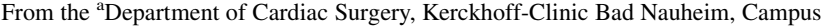
Kerckhoff, University of Giessen, Bad Nauheim; and ${ }^{\mathrm{b}}$ Department of Vascular and Endovascular Surgery, University Hospital of Cologne, Cologne, Germany.

Disclosures: The authors reported no conflicts of interest.

The Journal policy requires editors and reviewers to disclose conflicts of interest and to decline handling or reviewing manuscripts for which they may have a conflict of interest. The editors and reviewers of this article have no conflicts of interest.

Received for publication Dec 30, 2020; revisions received Dec 30, 2020; accepted for publication Jan 4, 2021; available ahead of print Jan 6, 2021.

Address for reprints: Oliver J. Liakopoulos, MD, Department of Cardiac Surgery, Kerckhoff-Clinic Bad Nauheim, Campus Kerckhoff, University of Giessen, Benekestr. 2-8, 61231 Bad Nauheim, Germany (E-mail: o.liakopoulos@ kerckhoff-klinik.de).

JTCVS Techniques 2021;7:27-8

2666-2507

Copyright (C) 2021 The Authors. Published by Elsevier Inc. on behalf of The American Association for Thoracic Surgery. This is an open access article under the CC BY-NCND license (http://creativecommons.org/licenses/by-nc-nd/4.0/).

https://doi.org/10.1016/j.xjtc.2021.01.001
}

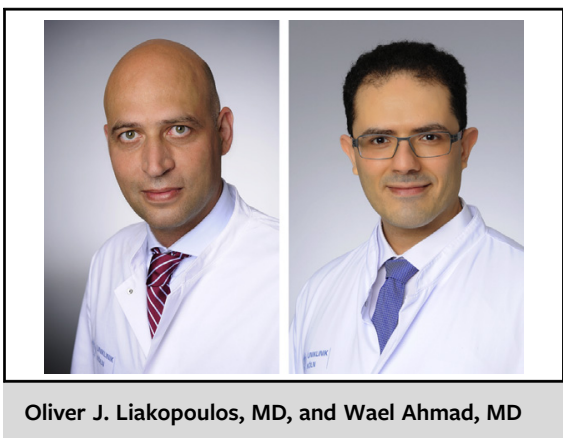

\section{CENTRAL MESSAGE \\ This case report demonstrates \\ the feasibility of a one-step \\ hybrid repair approach of acute \\ type A dissection with visceral \\ malperfusion.}

(endovascular-first strategy). ${ }^{1}$ Indeed, primary restoration of mesenteric perfusion with thoracic endovascular aortic repair or endovascular aortic fenestration without mesenteric vessel stenting has been recently proposed by 2 independent groups from Emory and Michigan in selected patients with stable AAD (ie, stable hemodynamics; no pericardial tamponade, aortic rupture or severe aortic regurgitation). ${ }^{4,5}$ The key advantage of the endovascular-first approach is that it offers a potential "bridge to decision" in stable patients and may avoid a futile open aortic surgery in the presence of a deleterious and irreversible mesenteric ischemia. On the downside, this strategy is not feasible in the majority of patients with AAD presenting with unstable hemodynamics, pericardial effusion, or aortic insufficiency, ${ }^{5,6}$ or in centers without or only limited access to experienced endovascular surgeons.

In this issue of the Journal, $\mathrm{Ni}$ and colleagues ${ }^{7}$ have evolved the endovascular-first technique to a one-step hybrid approach in a patient presenting with AAD complicated by severe aortic regurgitation, occlusion of the superior mesenteric artery, and right renal artery. The patient underwent, in a hybrid room setting, endovascular baremetal stenting of the superior mesenteric artery and right renal artery with successful restoration of visceral reperfusion. Subsequently, aortic root repair was completed and circulatory arrest for extensive arch repair was avoided by debranching of the supra-aortic vessels following endovascular arch repair with thoracic endovascular aortic repair (landing zone 0 ). The clinical course of the patient was uneventful and postoperative computed tomography scans 
before discharge revealed patent visceral vessels. The authors can be congratulated for their hybrid strategies that demonstrate the feasibility and efficacy of combining conventional aortic surgery with advanced endovascular repair in extensive AAD with MMP. Importantly, the successful one-step combination of both techniques underscores the importance of a dedicated aortic team with profound expertise in hybrid aortic repair techniques. Whether the endovascular-first strategy and one-stage hybrid approach will ultimately lead to improved outcomes in patients with AAD complicated by MMP when compared with conventional strategies needs to be evaluated in much larger series.

\section{References}

1. Perera NK, Galvin SD, Seevanayagam S, Matalanis G. Optimal management of acute type A aortic dissection with mesenteric malperfusion. Interact Cardiovasc Thorac Surg. 2014;19:290-4.
2. Czerny M, Schoenhoff F, Etz C, Englberger L, Khaladj N, Zierer A, et al. The impact of pre-operative malperfusion on outcome in acute type A aortic dissection: results from the GERAADA registry. J Am Coll Cardiol. 2015;65: 2628-35.

3. Di Eusanio M, Trimarchi S, Patel HJ, Hutchison S, Suzuki T, Peterson MD, et al. Clinical presentation, management, and short-term outcome of patients with type A acute dissection complicated by mesenteric malperfusion: observations from the international registry of acute aortic dissection. J Thorac Cardiovasc Surg. 2013; 145:385-90.

4. Leshnower BG, Keeling WB, Duwayri YM, Jordan WD Jr, Chen EP. The "thoracic endovascular aortic repair-first" strategy for acute type A dissection with mesenteric malperfusion: initial results compared with conventional algorithms. $J$ Thorac Cardiovasc Surg. 2019;158:1516-24.

5. Yang B, Rosati CM, Norton EL, Kim KM, Khaja MS, Dasika N, et al. Endovascular fenestration/stenting first followed by delayed open aortic repair for acute type A aortic dissection with malperfusion syndrome. Circulation. 2018;138: 2091-103.

6. Liakopoulos OJ, Kroener A, Sabashnikov A, Zeriouh M, Ahmad W, Choi YH, et al. Single-center experience with the frozen elephant trunk procedure in $111 \mathrm{pa}-$ tients with complex aortic disease. J Thorac Dis. 2020;12:5387-97.

7. Ni B, Gu J, Li M, Shao Y. Hybrid repair of acute type A aortic dissection with visceral malperfusion syndrome. J Thorac Cardiovasc Surg Tech. 2021;7: 22-4. 